\title{
Condition, disease, disability: how the label used to describe infertility may affect public support for fertility treatment coverage
}

\author{
Abigail C. Mancuso $^{1}$ (D) $\cdot$ Karen M. Summers ${ }^{1} \cdot$ Rebecca Chung $^{2} \cdot$ Ginny L. Ryan ${ }^{3} \cdot$ Aaron M. Scherer $^{4}$ \\ Received: 1 February 2021 / Accepted: 11 May 2021 / Published online: 26 May 2021 \\ (C) The Author(s), under exclusive licence to Springer Science+Business Media, LLC, part of Springer Nature 2021
}

\begin{abstract}
Purpose To assess public attitudes towards fertility treatment coverage and whether attitudes are influenced by infertility labels. Methods Cross-sectional, web survey-based experiment using a national sample of 1226 United States adults. Participants read identical descriptions about infertility, with the exception of random assignment to infertility being labeled as a "condition," "disease," or "disability." Participants then responded to questions measuring their beliefs and attitudes towards policies related to the diagnosis and treatment of infertility. We measured public support for infertility policies, public preference for infertility labels, and whether support differed by the randomly assigned label used. We also queried associations between demographic data and support for infertility policies.

Results Support was higher for insurance coverage of infertility treatments $(\mathrm{p}=.014)$ and fertility preservation $(\mathrm{p}=.017)$, and infertility public assistance programs $(\mathrm{p}=.036)$ when infertility was described as a "disease" or "disability" compared to "condition." Participants who were younger, were planning or trying to conceive, had a family member or friend with infertility, and/ or had a more liberal political outlook were more likely to support infertility policies. A majority of participants (78\%) felt the term "condition" was the best label to describe infertility, followed by "disability" (12\%). The least popular label was "disease" $(10 \%)$. Those preferring "condition" were older $(\mathrm{p}<.001)$, more likely to be non-Hispanic White $(\mathrm{p}=.046)$, and less likely to have an infertility diagnosis $(\mathrm{p}<.001)$.

Conclusion While less commonly identified as the best descriptors of infertility, labeling infertility as a "disease" or "disability" may increase support for policies that improve access to infertility care
\end{abstract}

Keywords Survey $\cdot$ Access to care $\cdot$ Infertility $\cdot$ Definitions

\section{Introduction}

Use of assisted reproductive technology (ART) in the United States (US) continues to increase, with over 75,000 babies

Abigail C. Mancuso

Abigail-mancuso@uiowa.edu

1 Department of Obstetrics and Gynecology, University of Iowa Hospitals and Clinics, 200 Hawkins Dr, Iowa City, IA 52241, USA

2 Department of Obstetrics and Gynecology, University Hospitals Cleveland Medical Center, 11100 Euclid Ave, Cleveland, OH 44106, USA

3 Department of Obstetrics and Gynecology, University of Washington School of Medicine, 1959 NE Pacific Street, Seattle, WA 98195, USA

4 Department of Internal Medicine, University of Iowa Hospitals and Clinics, 200 Hawkins Dr, Iowa City, IA 52241, USA born following ART in 2016 compared to 54,000 a decade earlier $[1,2]$. Despite increasing ART utilization in the US, infertility treatments remain inaccessible to a large proportion of the population due to high costs of treatment with low public funding compared to other countries [3]. There are racial and ethnic disparities in ART usage, with Black, Hispanic, and American Indian/Alaska Native women utilizing ART less than White women [4]. Infertility insurance mandates have been shown to decrease these disparities and improve access to infertility treatments [5-7]. Currently, 19 states have infertility insurance laws, 13 have in vitro fertilization (IVF) insurance laws, and only 10 have laws mandating coverage for fertility preservation prior to medical treatment that may cause infertility [8], demonstrating the need for policy changes that could improve access to fertility treatments in the US.

There is a need for stronger public policies to improve prevention, detection, and management of infertility and 
decrease the aforementioned disparities in access to care, and both the World Health Organization (WHO) and Centers for Disease Control and Prevention (CDC) have stated that infertility is a public health issue [9-11]. Elected officials who drive policy change are influenced by public opinion [12, 13], and thus, swaying public opinion on fertility-related issues could lead to improvements in care. Research in other areas of medicine has demonstrated that how a health issue is labeled has an impact on how people respond to it [14-17]. For instance, labeling a hypothetical pandemic influenza strain with a scientific or exotic-sounding name rather than a name based on the animal reservoir increased worry and vaccination intentions [15]. The International Committee for Monitoring Assisted Reproductive Technologies (ICMART) [18], states "the way some terms are defined can have an impact on their acceptance and understanding, not only by patients and their health care providers but also by the public and their policymakers, potentially affecting the manner in which reproductive medicine is practiced and accepted at country level." Thus, careful thought should be given to how we label infertility, as this may have potential to influence public support for infertility-related policies

Although the ICMART, CDC, and WHO argue for defining infertility as a disease of the reproductive system which can lead to disability $[9,10,18]$, there is little research on how the public defines infertility and if the definition in use can change public opinion. The purpose of our study was to query how a community sample of US adults label infertility and to identify factors associated with US public perceptions of infertility and fertility treatments, including the potential impact of labels on these perceptions. Specifically, we sought to determine if labeling infertility as a "disease," "disability," or "condition" changed public attitudes towards infertility and infertility-related policies.

\section{Materials and methods}

\section{Recruitment}

Participants aged 18 or older were recruited using Qualtrics ${ }^{\circledR}$ Research Services (http://www.qualtrics.com/). Our recruitment target was 1200 participants (400 per infertility label), with quotas for race, age, and gender to obtain a sample representative of these demographics for the United States population. A sampling algorithm was used to identify and invite participants until each quota was reached. Recruitment occurred over a 2-week period in April 2019.

Qualtrics ${ }^{\circledR}$ utilizes market research panels to recruit a majority of participants, although social media is occasionally used to gather respondents. Potential respondents may be notified by an email invitation, by signing into a panel portal, or by phone application notifications. They are informed how long the survey is expected to take and what incentives are available. Upon completion, participants were compensated based on their existing panel member agreements. These incentives vary by the length of survey and specific panelist profile, and compensation could include cash, airline miles, gift cards, redeemable points, charitable donations, sweepstakes entrance, and vouchers. Surveys were screened to drop those completed in less than half of the median survey completion time or for other problematic response patterns (e.g., uniform answers for every question). This study received exempt status by the Institutional Review Board (IRB) at the University of Iowa.

\section{Survey and demographics}

The survey was programmed using the Qualtrics ${ }^{\circledR}$ survey platform and had an estimated completion time of $15 \mathrm{~min}$. Eligible participants were given a link to the survey, which initially directed them to introductory information about the study, including the following purpose statement: "to investigate factors that may shape beliefs and attitudes about infertility and other reproductive health issues." To avoid potentially biasing participant responses, participants were not told until the end of the study that one of the study objectives was to determine the effect of their assigned infertility label on their responses. Participants were informed of the anonymous nature of the survey and were told they were free to stop the survey at any point and could skip questions they preferred not to answer.

Participants who wished to participate then answered screening demographic questions (age, sex, gender identity, race, and ethnicity) for the quotas mentioned above.

Additional demographic information obtained at the end of the study included marital status, pregnancy status, religiosity, political ideology, education, income, employment status, and employment in healthcare. Participants were also asked if they had ever been diagnosed with infertility and if they had a close family member or friend ever diagnosed with infertility.

\section{Design and randomly assigned label}

Following the screener questions but prior to answering questions regarding their beliefs on different infertility-related policies (see Measures below), the subjects read a short introductory description about infertility. The infertility description and survey items were identical across experimental conditions, the exception being whether infertility was labeled as a "disease," "disability," or "condition" within the infertility description (see Supplemental Appendix). Participants were randomly assigned to one of the three labels by the Qualtrics system. 


\section{Measures}

\section{Attitudes towards insurance cost-sharing}

Participants were asked how they thought costs should be split between patients and health insurance, with a sliding scale from patient pays $100 \%$ (0) to health insurance pays $100 \%$ (100). Participants were then asked whether they thought different types of health insurance should pay for infertility treatments: (1) government-funded (2) private employer; (3) large business employer; (4) small business employer; (5) religious organization. Responses to this measure, and all subsequent measures, were on a $0-100$ scale ranging from "strongly disagree" $(0)$ to "strongly agree" (100).

\section{Attitudes towards fertility preservation coverage}

After a short introduction about fertility preservation, participants were asked whether health insurance should help cover fertility preservation for patients under different scenarios: (1) delay in having kids to focus on career, (2) delay in having kids until more financially stable, (3) delay in having kids to focus on advancing education, (4) delay in having kids until they have a stable partner to help parent, or (5) medical treatment that might affect fertility, like chemotherapy.

\section{Attitudes towards public assistance}

Participants were asked about public assistance programs and if these should be available to help pay for fertility treatments under different conditions: (1) persons who are unable to afford infertility treatment, (2) persons planning to undergo cancer treatments that may cause infertility, (3) Veterans who are unable to afford infertility treatment, (4) Veterans who sustained an injury during service that affected fertility.

\section{Participant preferred label}

After completion of the questions on attitudes towards infertility policies, participants were asked which of the three labels ("condition," "disease," or "disability") they thought best defined infertility. This question was separate from the randomly assigned infertility label given to each participant in the introductory statement about infertility.

\section{Statistical analysis}

For the linear regression analysis, responses were averaged to create an aggregate value for insurance coverage support (Cronbach's $\alpha=0.80$ ), fertility preservation insurance coverage support $(\alpha=0.86)$, and fertility treatment public assistance support $(\alpha=0.80)$, each with a range from 0 to 100 .
To test for group differences based on infertility label (experimentally assigned label and preferred label separately), oneway ANOVAs were used for continuous variables and chisquare analyses for categorical variables. Generalized linear models included the following independent variables: randomly assigned infertility label used in the introductory statement, participant preferred label, participant self-identified age, sex, race, education level, marital status, pregnancy status, income, infertility experience, employment, employment in healthcare, political ideology, and religiosity (Supplementary Table S1).

\section{Results}

\section{Response rate and demographic characteristics of the sample}

Out of the 1851 participants who completed the screener items, 128 participants were excluded for age $<18$ years old. Of the 1723 participants who advanced past the screener questions, 1226 completed the survey ( $71 \%$ completion rate) (see Table 1 for demographics). Average age of participants was 46.2 years old with a range of 18-99. Split was even among participants assigned male and female at birth at $50.4 \%$ and $49.6 \%$ respectively. Of those, $48.5 \%$ identified as female, $50.4 \%$ as male, $0.5 \%$ as transgender, $0.5 \%$ as non-binary, and $0.2 \%$ of participants reported other gender identity.

\section{Randomly assigned label}

Of the 1226 participants included, 422 participants were randomly assigned to the infertility description which used the label "condition," 394 to the label "disease," and 410 to "disability." There was no difference in age, sex, race, average income, religiosity, political ideology, employment status, working in healthcare, education, marital status, or region of the US currently living between groups randomly assigned to different labels (Table 1). More participants randomly assigned to the label "disability" (13.9\%) had a personal history of infertility compared to "disease" $(8.6 \%)$ and "condition" (9.0\%), and more participants randomly assigned to "disease" $(31.0 \%)$ had a family or friend diagnosed with infertility compared to "disability" $(24.4 \%)(\mathrm{p}=.038)$. More participants randomly assigned to "condition" $(12.4 \%)$ were currently pregnant compared to "disease" $(7.0 \%)$, and more randomly assigned to "disease" (11.7\%) were planning or trying to conceive compared to "disability" $(7.4 \%)(\mathrm{p}=.033)$.

\section{Participant preferred label}

Out of the 1221 participants who answered the preferred infertility label question, a majority $(957,78.4 \%)$ felt the term "condition" best defined infertility. This was followed by "disability" 


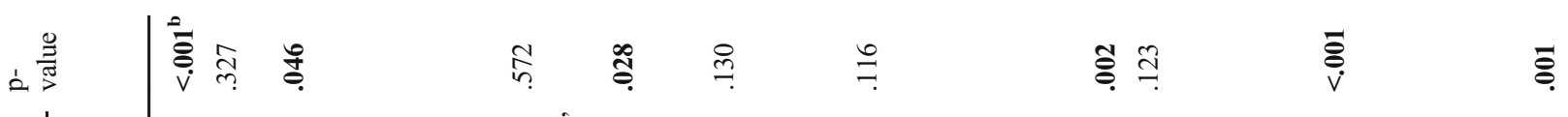

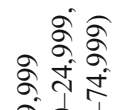

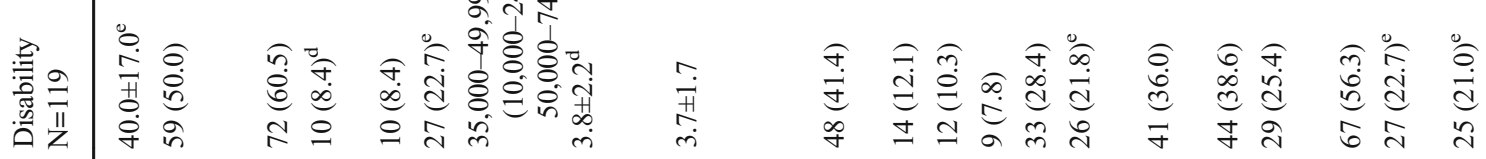

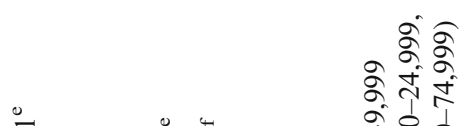

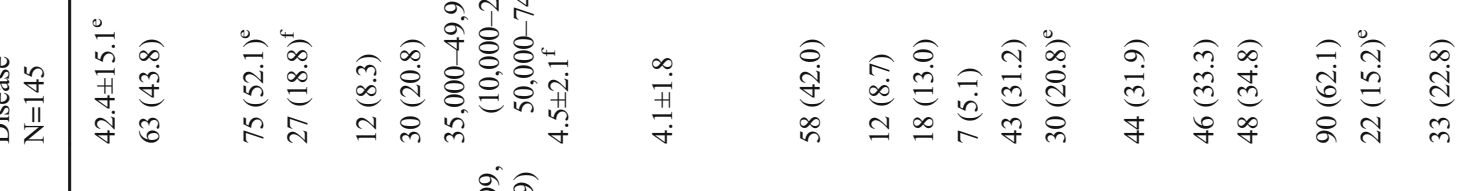

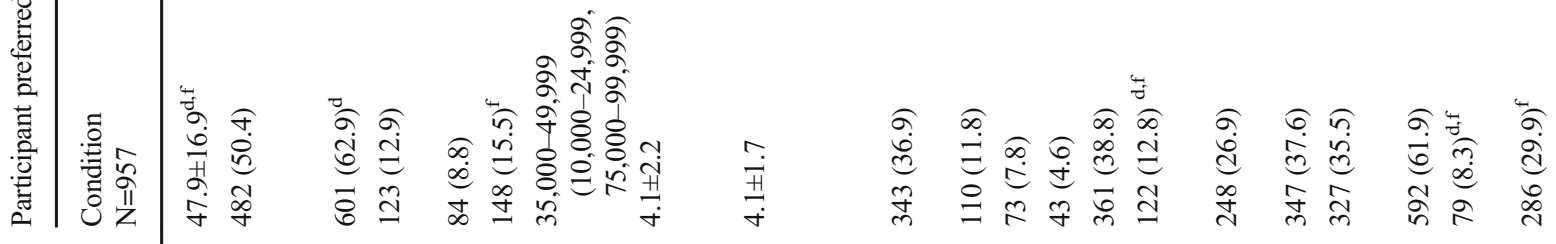

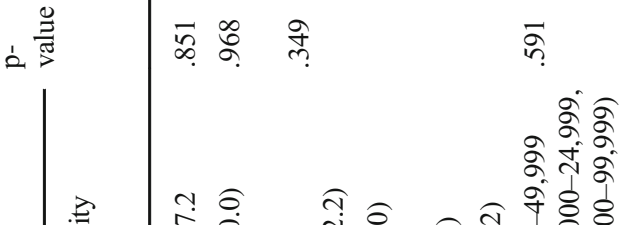

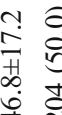

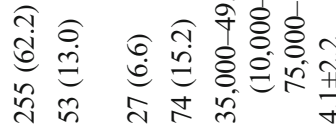

尊

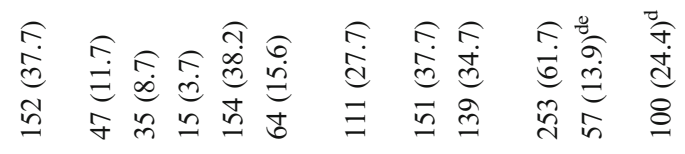

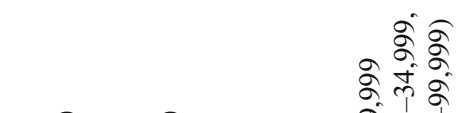

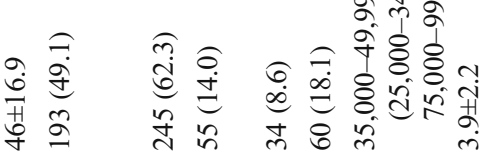

守

ठิ़े के

$\stackrel{\infty}{\stackrel{\infty}{0}}$

\% a

के
के
के

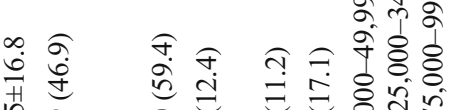

में

究

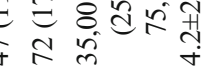

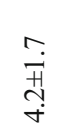

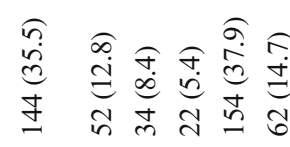

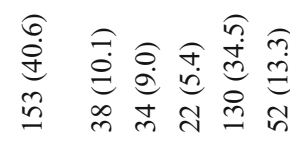

离

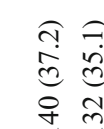

毒

ले

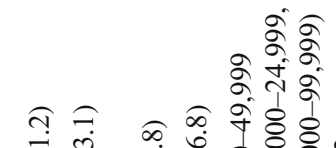

근

它

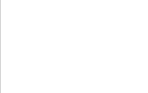

迶

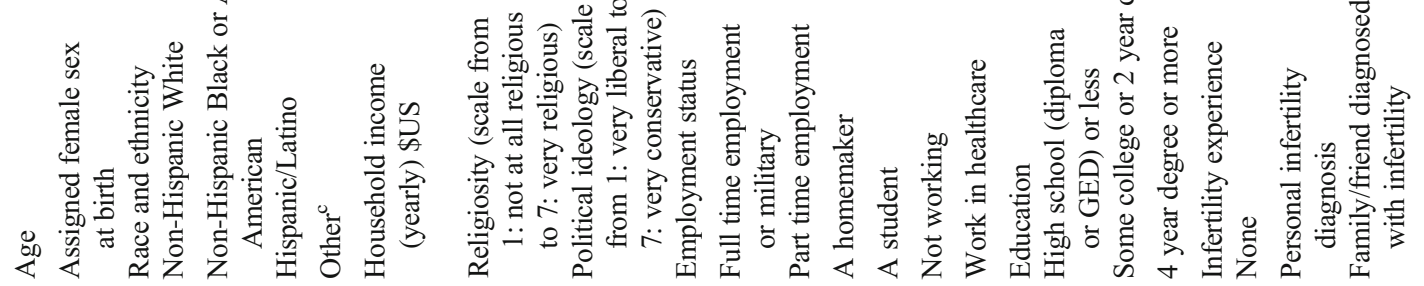

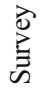

产 


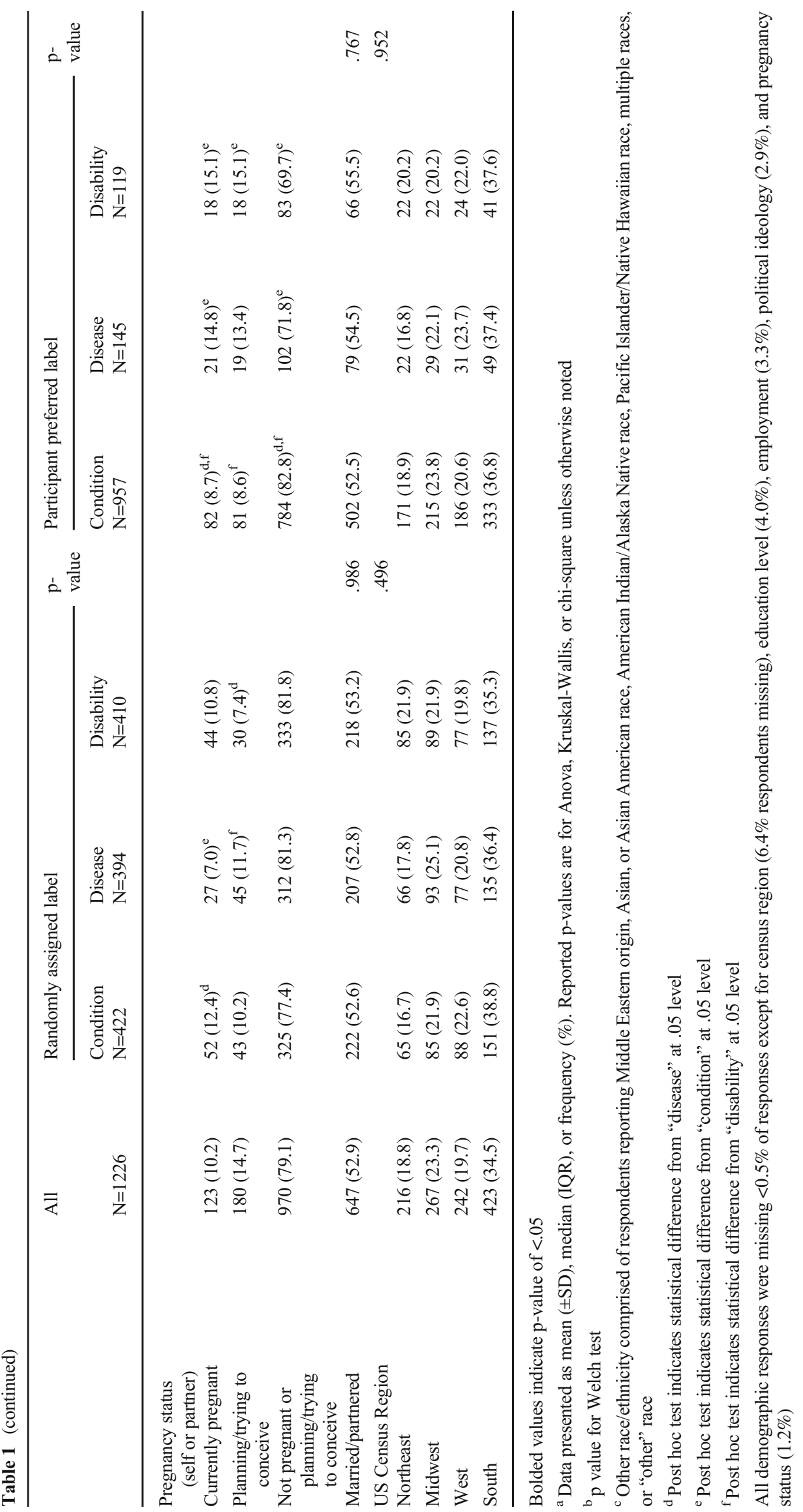


$(145,11.9 \%)$ and "disease" (119, 9.7\%) (Fig. 1). Participants that were older preferred the label "condition" (mean age \pm standard deviation of $47.9 \pm 16.9$ ), compared to disease (42.4 $\pm 15.1)$, and disability $(40.0 \pm 17.0)(\mathrm{p}<.001)$. Participants who preferred the label "condition" were more likely to be nonHispanic White and less likely to be in the "other" race category; those choosing the label "disease" were more likely to be nonHispanic Black or African American, and those choosing the label "disability" were more likely to be in the "other race" category and less likely to be non-Hispanic Black or African American ( $\mathrm{p}=.046$ ). Those choosing "condition" were less likely to have a personal history of infertility and more likely to have a family or friend with infertility, and those choosing "disability" were more likely to have a personal infertility diagnosis $(p=<.001)$. Those choosing "condition" were less likely to be currently pregnant or planning or trying to conceive $(\mathrm{p}=.001)$ and were less likely to work in healthcare $(\mathrm{p}=.002)$. Those choosing "disease" were more religious than those choosing the other two labels $(\mathrm{p}=.028)$

There were no differences in preferences based on sex, household income, political ideology, employment status, education, marital status, or region of the US in which they resided when it came to choosing which label best defines infertility (Table 1).

\section{Infertility insurance coverage support}

Figure 2 shows the average support of infertility policies (overall and by randomly assigned label). In general, participants supported insurance coverage for fertility treatment across insurance types, with a mean \pm standard deviation (SD) of $58.0 \pm 23.1$ ( $0=$ no support, $100=$ complete support). Participants favored insurance payment for fertility treatment over patient self-payment, with a mean of $66.7 \pm 27.2(0=$ costs covered completely by the patient, $100=$ costs covered completely by insurance) (Supplementary Figure S1). Looking at specific insurance types, most support was given for private insurance (70.0 \pm 26.9$)$, followed by "employer:

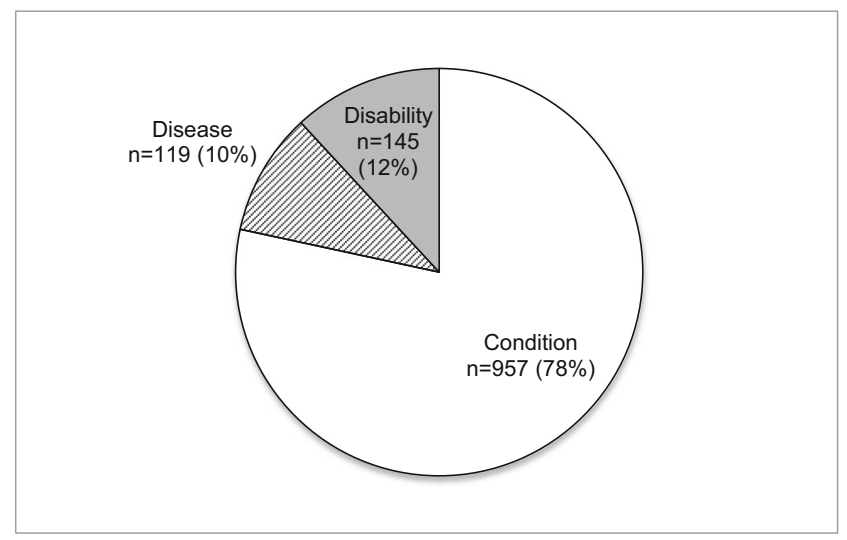

Fig 1 Which label best describes how you think about infertility large business" (61.8 \pm 30.9$)$, government-funded insurance $(57.4 \pm 33.0)$, then "employer: religious organization" (52.4 \pm 32.7 ) with the least support given for "employer: small business" (48.7 \pm 31.1$)(\mathrm{p}<.001)$ (Supplementary Figure S2).

Table 2 shows the regression results for fertility policy support. Support for infertility insurance coverage was significantly increased among participants randomly assigned to the label "disability" in the introductory statement about infertility, as well as among participants who were younger, planning or trying to conceive, those with a family or friend with infertility, and those with a more liberal political outlook. Participants who preferred the "disability" label were also more likely to support infertility insurance coverage.

\section{Fertility preservation coverage support}

Overall, the participants supported insurance coverage for fertility preservation, with a mean of $60.20 \pm 24.2$ (Fig. 2). Participants most strongly supported fertility preservation for patients prior to "medical treatment that might affect fertility, like chemotherapy" (70.1 \pm 26.9$)$ followed by "delay in having kids until more financially stable" (62.4 \pm 30.6$)$, "delay in having kids until they have a stable partner to help parent" (60.0 \pm 31.5 ), "delay in having kids to focus on advancing education" (55.9 \pm 31.2 ), and "delay in having kids to focus on career" (53.2 \pm 31.5$)(p<.001)$ (Supplementary Figure S3).

After adjustment for other variables, factors associated with support for fertility preservation coverage included random assignment to the label "disease," younger age, lower formal education levels, history of planning or trying to conceive, higher levels of liberal political ideology, and increased religiosity (Table 2).

\section{Infertility public assistance support}

Participants generally supported public assistance programs for fertility treatments, with a mean of $70.45 \pm 21.2$ (Fig. 2). Participants were most supportive of infertility public assistance for "Veterans who sustained an injury during service that affected fertility" (79.1 \pm 23.1$)$ followed by "Veterans who are unable to afford infertility treatments" (72.8 26.1$)$, "persons who are going to undergo cancer treatments that may cause infertility" (69.2 \pm 27.4$)$, and "persons who are unable to afford infertility treatment" $(60.8 \pm 30.1)(\mathrm{p}<.001)$ (Supplementary Figure S4).

After adjustment for other variables, factors that increased support for infertility public assistance included assignment to the label "disease," younger age, planning or trying to conceive, history of a family or friend with infertility, liberal political outlook, and preference for the label "disability" (Table 2). Unmarried participants had lower levels of support. 
Fig 2 Infertility policy support by randomly assigned label.

Aggregate scales created from averaging responses to similar measures ranging from $0=$ no support to $100=$ strong support

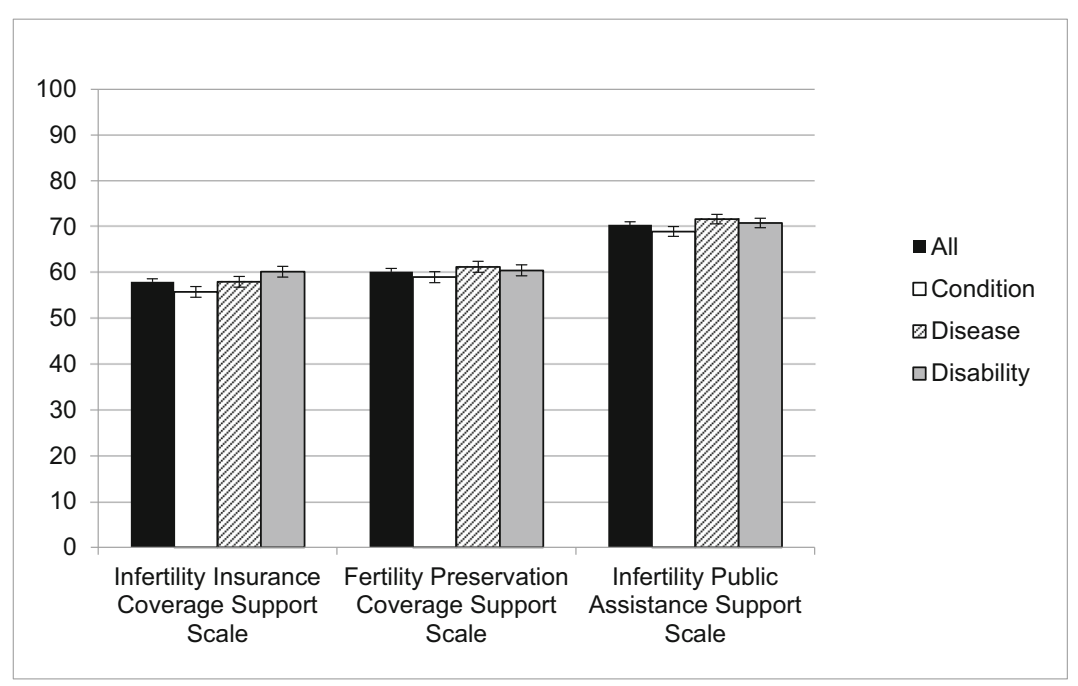

Aggregate scales created from averaging responses to similar measures ranging from $0=$ no support to $100=$ strong support

\section{Discussion}

The American Society for Reproductive Medicine (ASRM) task force on Diversity, Equity, and Inclusion calls for reducing health care disparities through measures such as continuing to support universal coverage for infertility and continuing to expand advocacy efforts for inclusive policies [19]. In our national, online sample of US adults, we found that labeling infertility as a "disease" or "disability" rather than as a "condition" was associated with increased support for infertility treatment insurance coverage, fertility preservation insurance coverage, and public assistance support for infertility treatments. At the same time, we found that a majority of participants preferred the label "condition" to describe infertility, despite the negative effect of this label on support for such public policies relative to the "disease" and "disability" labels. Thus, our study suggests that labels may have the power to influence public perception and lead to increased support of policies that improve access to infertility treatments.

While these differences may seem semantic, ICMART has highlighted that consistency in defining infertility as a "disease of the reproductive system, which can lead to disability" during debates and decision making can help improve access to fertility treatments at regional and national levels [20]. Other areas of medicine have also seen improvements in support through the process of rebranding; for instance, redefining alcoholism as a chronic disease rather than a lifestyle choice or character flaw led to improvements in multidisciplinary treatments, pharmacologic treatments, increased federal research funding, and public and health care awareness [21]. Similarly, people who were exposed to a message describing obesity as a disease that causes health problems rather a weakness in obese people themselves were more likely to support public policies aimed at reducing obesity [22]. While these diseases differ from infertility in that they are more visible and have larger impacts on health care costs, infertility has similarly been erroneously branded a lifestyle issue or elective desire. Those in reproductive medicine understand the devastating effects of infertility on patients, including increased risk of depression and anxiety at levels similar to those of cancer patients [23, 24]. Our study suggests that continued efforts to label infertility as a disease and disability may lead to similar improvements in public support.

Despite the efforts of major organizations to label infertility as a disease, an international survey completed in 2000 showed that less than half (38\%) of people perceived infertility as a disease [25]. While over 15 years have passed since this study, those findings are consistent with ours; specifically, only $10 \%$ of participants in our study perceived infertility as a disease and $12 \%$ as a disability, showing there is room for improvement in public discourse. Models proven to advance policies and promote behavioral change suggest the following formula: identifying targeted audiences to help focus resources, developing an effective message that would resonate based on values, and selecting the right messenger and right channel so messages effectively reach the desired audience [26]. Results from our study can help identify audience segments to target future message campaigns identifying infertility as a disease, with a goal of garnering increased support for infertility insurance coverage mandates.

Our study found that although those with a personal history of infertility were more likely to perceive infertility as a disease or disability, a personal history of infertility was not associated with infertility policy support. In a study by Nachtigall et. al., only $55 \%$ of those treated for infertility were in support of infertility insurance coverage, with $16 \%$ opposed and 29\% uncertain [27]. Those with insurance coverage were more likely to support insurance coverage and those that 
Table 2 Factors associated with support for fertility policies

\begin{tabular}{|c|c|c|c|c|c|c|}
\hline \multirow[t]{2}{*}{ Factor } & \multicolumn{2}{|l|}{$\begin{array}{l}\text { Infertility insurance } \\
\text { coverage support }\end{array}$} & \multicolumn{2}{|c|}{$\begin{array}{l}\text { Fertility preservation } \\
\text { coverage support }\end{array}$} & \multicolumn{2}{|l|}{$\begin{array}{l}\text { Infertility public } \\
\text { assistance support }\end{array}$} \\
\hline & $\mathrm{B}(95 \% \mathrm{CI})$ & p-value & $\mathrm{B}$ & p-value & $\mathrm{B}$ & p-value \\
\hline \multicolumn{7}{|l|}{ Randomly assigned label } \\
\hline Condition & Reference & -- & Reference & -- & Reference & -- \\
\hline Disease & $1.7(-2.0-5.4)$ & .363 & $4.6(0.8-8.4)$ & 0.017 & $3.7(0.2-7.1)$ & .036 \\
\hline Disability & $4.6(0.9-8.2)$ & .014 & $2.5(-1.2-6.3)$ & 0.187 & $2.4(-1.0-5.8)$ & .162 \\
\hline \multicolumn{7}{|l|}{ Participant preferred label } \\
\hline Condition & Reference & -- & Reference & -- & Reference & -- \\
\hline Disease & $1.4(-6.3-9.1)$ & .724 & $4.6(-3.4-12.6)$ & 0.259 & $5.4(-1.8-12.6)$ & .140 \\
\hline Disability & $14.7(5.2-24.4)$ & .003 & $6.5(-3.5-16.5)$ & 0.204 & $11.8(2.8-20.9)$ & .010 \\
\hline Age & $-0.2(-0.4--0.1)$ & $<.001$ & $-0.3(-0.4-0.1)$ & $<0.001$ & $-0.1(-0.2--0.0)$ & .009 \\
\hline \multicolumn{7}{|l|}{ Sex } \\
\hline Male & Reference & -- & Reference & -- & Reference & -- \\
\hline Female & $-0.5(-3.4-2.5)$ & .762 & $-1.5(-4.6-1.5)$ & 0.333 & $2.3(-0.4-5.1)$ & .097 \\
\hline \multicolumn{7}{|l|}{ Race } \\
\hline White & Reference & -- & Reference & -- & Reference & -- \\
\hline Black & $3.8(-0.7-8.2)$ & 1.70 & $4.0(-0.6-8.5)$ & 0.089 & $1.6(-2.5-5.6)$ & .454 \\
\hline Hispanic & $-0.9(-6.0-4.3)$ & .74 & $-3.4(-8.7-2.0)$ & 0.218 & $1.7(-3.1-6.5)$ & .480 \\
\hline Other & $1.3(-2.6-5.2)$ & .66 & $3.3(-0.8-7.4)$ & 0.113 & $-1.1(-4.7-2.6)$ & .574 \\
\hline \multicolumn{7}{|l|}{ Education } \\
\hline 4-year degree or more & Reference & -- & Reference & -- & Reference & -- \\
\hline Some college/2 year degree & $-3.1(-6.4-0.2)$ & .064 & $1.0(-2.5-4.4)$ & 0.588 & $0.1(-3.0-3.1)$ & .969 \\
\hline High school or less & $-0.3(-4.2-3.6)$ & .867 & $5.4(1.3-9.4)$ & 0.009 & $1.6(-2.0-5.2)$ & .383 \\
\hline \multicolumn{7}{|l|}{ Marital status } \\
\hline Married & Reference & -- & Reference & -- & Reference & -- \\
\hline Not currently married & $-2.7(-5.6-0.3)$ & .074 & $-3.1(-6.1-0.0)$ & 0.050 & $-3.2(-6.0--0.5)$ & .021 \\
\hline \multicolumn{7}{|l|}{ Pregnancy status } \\
\hline Not pregnant & Reference & -- & Reference & -- & Reference & -- \\
\hline Planning/trying to conceive & $7.4(2.4-12.5)$ & .004 & $5.6(0.3-10.8)$ & 0.037 & $5.7(1.1-10.4)$ & .016 \\
\hline Currently pregnant & $-1.5(-6.4-3.5)$ & .564 & $0.8(-4.4-6.1)$ & 0.753 & $-0.5(-5.2-4.2)$ & .828 \\
\hline Income & $-0.5(-1.3-0.3)$ & .245 & $-0.7(-1.6-0.1)$ & 0.101 & $0.1(-0.7-0.9)$ & .767 \\
\hline \multicolumn{7}{|l|}{ Infertility experience } \\
\hline None & Reference & -- & Reference & -- & Reference & -- \\
\hline Personal infertility diagnosis & $4.3(-3.2-11.9)$ & .260 & $3.5(-1.6-0.1)$ & 0.395 & $2.4(-4.6-9.5)$ & .500 \\
\hline Family/friend with infertility & $4.0(0.9-7.1)$ & .012 & $0.5(-2.7-3.7)$ & 0.745 & $3.1(0.2-6.0)$ & .036 \\
\hline \multicolumn{7}{|l|}{ Employment } \\
\hline Full time/military & Reference & --- & Reference & -- & Reference & -- \\
\hline Student & $-4.9(-11.8-2.0)$ & .166 & $-4.0(-12.2-2.3)$ & 0.177 & $-5.9(-12.4-0.5)$ & .073 \\
\hline Part time employment & $-1.0(-5.7-3.7)$ & .671 & $-3.6(-8.4-1.3)$ & 0.149 & $-4.0(-8.3-0.4)$ & .073 \\
\hline Homemaker & $0.7(-4.8-6.1)$ & .812 & $-5.2(-10.9-0.5)$ & 0.073 & $2.5(-2.6-7.6)$ & .342 \\
\hline Not working & $0.4(-3.2-4.1)$ & .812 & $-0.2(-4.0-3.7)$ & 0.935 & $1.4(-2.1-4.9)$ & .426 \\
\hline \multicolumn{7}{|l|}{ Employment in healthcare } \\
\hline No & Reference & -- & Reference & -- & Reference & -- \\
\hline Yes & $-0.8(-4.8-3.2)$ & .685 & $3.4(-0.7-7.6)$ & 0.100 & $0.6(-3.1-4.3)$ & .752 \\
\hline Political ideology & $-2.0(-2.8--1.1)$ & $<.001$ & $-2.0(-2.9--1.1)$ & $<0.001$ & $-1.3(-2.1--0.5)$ & .002 \\
\hline \multicolumn{7}{|c|}{ Very liberal (1) to very conservative (7) } \\
\hline Religiosity & $0.7(-0.01-1.3)$ & .055 & $0.8(0.1-1.5)$ & 0.025 & $0.5(-0.1-1.2)$ & .085 \\
\hline \multicolumn{7}{|l|}{ Not at all religious (1) to } \\
\hline Very religious (7) & & & & & & \\
\hline
\end{tabular}

Bolded values indicate $\mathrm{p}$-value of $<.05$ 
supported coverage were more likely to view infertility as a disease similar to other medical illnesses or diseases [27]. Those that did not support coverage saw infertility treatments as a "quality of life" issue rather than a medical issue [27], again supporting the idea that those who saw infertility as a disease were more likely to support infertility policies, even among people undergoing IVF treatments.

Other factors in our study associated with support for improved coverage of fertility treatments included younger age, planning or trying to conceive, having a family or friend with infertility, stronger liberal political ideology, and higher religiosity. A recent European study assessing public attitudes of ART also found favorable attitudes towards IVF and public funding with younger age groups [28]. It may simply be that infertility policies are more important to the younger generation that is contemplating, actively pursuing, or still desirous of future childbearing. This is consistent with our finding of stronger support among those planning to conceive compared to those who were currently pregnant or not planning a pregnancy. However, it also may be the case that as infertility discussion and treatments have become less stigmatized and more mainstream, younger generations are more supportive of coverage for infertility treatments.

Interestingly, those who self-identified as religious were more likely to support fertility preservation and more likely to prefer the term "disease" and least likely to prefer "disability." While certain religious groups may be more likely to feel that ART is a violation of their religious beliefs [29], people who consider themselves more religious may also place more importance on the ability to have children in the future [30]. Although participants who had more liberal political views were no more likely to prefer the labels "disease" or "disability" than those with more conservative political views, they were more likely to support infertility treatment coverage. Differences in health policy support by political ideology have been seen in other fields of medicine; for instance, in one study, liberal participants were more likely to support policies to reduce the consumption of sugary drinks when the drinks were labeled "soda", while conservative support for these policies was higher when the "sugar-sweetened beverage" label was used, but regardless of label, liberal participants were still more likely to support these policies [16]. Policy support has strong political ideological undertones. Rather than trying to change policy beliefs directly, the consistent and frequent use of labels by the medical community and in the media may be a more indirect, practical method to improve policy support.

Overall, it is encouraging that there was support for policies which would improve access to infertility care by increasing insurance coverage, fertility preservation, and public assistance programs. Through our use of sampling quotas for race, age, and gender, we were able to obtain a demographically diverse sample representative of the United States population. However, using an internet-based survey has its limitations and may result in some level of sampling bias, as people who have access to the internet, and those motivated to complete surveys, are more likely to participate. Despite this fact, about $90 \%$ of the 2019 US population had internet access and online surveys are more representative of the US population than clinic-based studies [31]. Strengths of this study include a relatively large sample size with a demographically diverse population, and the use of an experimental method to assess the causal effect of the label used to describe infertility on public opinion.

Further research is needed to confirm effective message campaigns for targeted audience segments, including identifying messaging that resonates most with audiences, as well as appropriate messengers and channels. Potential campaigns may include a social media campaign describing infertility as disease, grass roots campaigns which empower people impacted by infertility to discuss infertility as disease within their social networks, and partnerships with media and educators to advocate for consistent labeling of infertility as a disease.

\section{Conclusion}

While a majority of participants felt that "condition" was the label that best described infertility, those who were randomly assigned to view, or preferred, the "disability" and "disease" labels to describe infertility were more likely to support public policies improving coverage for infertility treatments. Relabeling infertility while advocating for equal access to infertility care may help sway public opinion, and ultimately policymakers, to support policies that make fertility treatments available for everyone.

Supplementary Information The online version contains supplementary material available at https://doi.org/10.1007/s10815-021-02231-z.

Author contribution All authors contributed to the study conception and design. Data analysis was carried out by Karen Summers. The first draft of the manuscript was written by Abigail Mancuso and all authors commented on the previous versions of the manuscript. All authors read and approved the final manuscript.

Funding This work was funded by Molinaro-Blonigan Fund at the University of Iowa Hospitals and Clinics.

Availability of data and material Data available on request.

Code availability Not applicable.

\section{Declarations}

Ethics approval This study received exempt status by the Institutional Review Board (IRB) at the University of Iowa. 
Consent to participate Not applicable.

Consent for publication Not applicable.

Conflict of interest The authors declare no competing interests.

\section{References}

1. Sunderam S, Kissin DM, Zhang Y, Folger SG, Boulet SL, Warner L, et al. Assisted reproductive technology surveillance - United States, 2016. MMWR Surveill Summ. 2019;68(4):1-23. https:// doi.org/10.15585/mmwr.ss6804a1.

2. Sunderam S, Chang J, Flowers L, Kulkarni A, Sentelle G, Jeng G, et al. Assisted reproductive technology surveillance-United States, 2006. MMWR Surveill Summ. 2009;58(5):1-25.

3. Chambers GM, Sullivan EA, Ishihara O, Chapman MG, Adamson GD. The economic impact of assisted reproductive technology: a review of selected developed countries. Fertil Steril. 2009;91(6): 2281-94. https://doi.org/10.1016/j.fertnstert.2009.04.029.

4. Dieke AC, Zhang Y, Kissin DM, Barfield WD, Boulet SL. Disparities in assisted reproductive technology utilization by race and ethnicity, United States, 2014. A Commentary Journal of women's health (2002). 2017;26(6):605-8. https://doi.org/10. 1089/jwh.2017.6467.

5. Hamilton BH, McManus B. The effects of insurance mandates on choices and outcomes in infertility treatment markets. Health Econ. 2012;21(8):994-1016. https://doi.org/10.1002/hec.1776.

6. Hammoud AO, Gibson M, Stanford J, White G, Carrell DT, Peterson M. In vitro fertilization availability and utilization in the United States: a study of demographic, social, and economic factors. Fertil Steril. 2009;91(5):1630-5. https://doi.org/10.1016/j. fertnstert.2007.10.038.

7. Martin JR, Bromer JG, Sakkas D, Patrizio P. Insurance coverage and in vitro fertilization outcomes: a U.S. perspective. Fertil Steril. 2011;95(3):964-9. https://doi.org/10.1016/j.fertnstert.2010.06.030.

8. RESOLVE: The National Infertility Association. Infertility coverage by state. Available at: https://resolve.org/what-are-my-options/ insurance-coverage/infertility-coverage-state/. Accessed October 24, 2020

9. World Health Organization (WHO). Infertility is a global public health issue 2020. Available at: https://www.who.int/ reproductivehealth/topics/infertility/perspective/en/\#: :text= Infertility $\% 20$ is $\% 20$ defined $\% 20$ as $\% 20$ a,in $\% 201$ ower $\%$ 20resource\%20settings\%20worldwide. Accessed October 24, 2020

10. Centers for Disease Control and Prevention. National Public Health Action Plan for the Detection, Prevention, and Management of Infertility, Atlanta, Georgia: Centers for Disease Control and Prevention; June 2014

11. Macaluso M, Wright-Schnapp TJ, Chandra A, Johnson R, Satterwhite CL, Pulver A, et al. A public health focus on infertility prevention, detection, and management. Fertil Steril. 2010;93(1): 16.e1-0. https://doi.org/10.1016/j.fertnstert.2008.09.046.

12. Benagiano G, Farris M. Public health policy and infertility. Reprod BioMed Online. 2003;7(6):606-14. https://doi.org/10.1016/s14726483(10)62082-2.

13. Woolley M, Propst SM. Public attitudes and perceptions about health-related research. JAMA. 2005;294(11):1380-4. https://doi. org/10.1001/jama.294.11.1380.

14. Nickel B, Barratt A, Copp T, Moynihan R, McCaffery K. Words do matter: a systematic review on how different terminology for the same condition influences management preferences. BMJ Open. 2017;7(7):e014129. https://doi.org/10.1136/bmjopen-2016014129 .

15. Scherer AM, Knaus M, Zikmund-Fisher BJ, Das E, Fagerlin A. Effects of influenza strain label on worry and behavioral intentions. Emerg Infect Dis. 2017;23(8):1425-6. https://doi.org/10.3201/ eid2308.170364.

16. Roh S, Niederdeppe J. The word outside and the pictures in our heads: contingent framing effects of labels on health policy preferences by political ideology. Health Commun. 2016;31(9):1063-71. https://doi.org/10.1080/10410236.2015.1037420.

17. Viswanath K, Emmons KM. Message effects and social determinants of health: its application to cancer disparities: Oxford University Press / USA; 2006. p. S238-S64.

18. Zegers-Hochschild F, Adamson GD, Dyer S, Racowsky C, de Mouzon J, Sokol R, et al. The international glossary on infertility and fertility care, 2017. Hum Reprod. 2017;32(9):1786-801. https://doi.org/10.1093/humrep/dex234.

19. Thomas MA, Alvero R, Anaya Y, Chang A, Darno J, Cebert Gaitors, M, Hammond C, Jackson-Bey T, Lanski AC, Leondires M, Middlebroook M, Comeaux Plowden LTC, Richard-Davis G, Thornton K, Wood JM. ASRM Task Force on Diversity, Equity, and Inclusion Issues Statement, Recommendations December 1 , 2020. https://www.asrm.org/globalassets/asrm/asrm-content/ about-us/pdfs/asrm-dei-task-force-report-11-30-2020.pdf

20. Zegers-Hochschild F, Adamson GD, de Mouzon J, Ishihara O, Mansour R, Nygren K, et al. International Committee for Monitoring Assisted Reproductive Technology (ICMART) and the World Health Organization (WHO) revised glossary of ART terminology, 2009. Fertil Steril. 2009;92(5):1520-4. https://doi. org/10.1016/j.fertnstert.2009.09.009.

21. Hurt RT, Edakkanambeth Varayil J, Mundi MS, Martindale RG, Ebbert JO. Designation of obesity as a disease: lessons learned from alcohol and tobacco. Current gastroenterology reports. 2014;16(11):415. https://doi.org/10.1007/s11894-014-0415-z.

22. McGlynn J, McGlone MS. Desire or Disease? Framing obesity to influence attributions of responsibility and policy support. Health Commun. 2019;34(7):689-701. https://doi.org/10.1080/10410236. 2018.1431025.

23. Domar AD, Zuttermeister PC, Friedman R. The psychological impact of infertility: a comparison with patients with other medical conditions. J Psychosom Obstet Gynaecol. 1993;14(Suppl):45-52.

24. Verma P, Rastogi R, Sachdeva S, Gandhi R, Kapoor R, Sachdeva S. Psychiatric morbidity in infertility patients in a tertiary care setup. J Clin Diagn Res. 2015;9(9):Vc01-vc6. https://doi.org/10.7860/ jcdr/2015/14290.6419.

25. Adashi EY, Cohen J, Hamberger L, Jones HW Jr, de Kretser DM, Lunenfeld B, et al. Public perception on infertility and its treatment: an international survey. The Bertarelli Foundation Scientific Board. Hum Reprod. 2000;15(2):330-4. https://doi.org/10.1093/humrep/ 15.2.330.

26. Campisteguy M. SK. Using strategic communication to advance behavioral, attitudinal, and systems change. In: Wright $\mathrm{T}$, Richardson JW, editor. School-based health care: Advancing educational success and public health APHA Press; 2012. p. 201-12

27. Nachtigall RD, MacDougall K, Davis A, Beyene Y. Expensive but worth it: older parent's attitudes and opinions about the costs and insurance coverage for in vitro fertility. Fertil Steril. 2011;97:82-7.

28. Fauser B, Boivin J, Barri PN, Tarlatzis BC, Schmidt L, LevyToledano R. Beliefs, attitudes and funding of assisted reproductive technology: public perception of over 6000 respondents from 6 European countries. PLoS One. 2019;14(1):e0211150. https://doi. org/10.1371/journal.pone.0211150. 
29. Galic I, Swanson A, Warren C, Negris O, Bozen A, Brown D, et al. Infertility in the Midwest: perceptions and attitudes of current treatment. Am J Obstet Gynecol. 2021. https://doi.org/10.1016/j.ajog. 2021.02.015.

30. Dutney A. Religion, infertility and assisted reproductive technology. Best Pract Res Clin Obstet Gynaecol. 2007;21(1):169-80. https://doi.org/10.1016/j.bpobgyn.2006.09.007.

31. Admon L, Haefner JK, Kolenic GE, Chang T, Davis MM, Moniz MH. Recruiting pregnant patients for survey research: a head to head comparison of social media-based versus clinic-based approaches. J Med Internet Res. 2016;18(12):e326. https://doi.org/ 10.2196/jmir.6593.

Publisher's note Springer Nature remains neutral with regard to jurisdictional claims in published maps and institutional affiliations. 